\section{Michigan Technological 18 85 University}

Michigan Technological University Digital Commons @ Michigan Tech

5-17-1965

\title{
Studies of the Moose and Wolves of Isle Royale, 1964-1965
}

Peter A. Jordan

Purdue University

Follow this and additional works at: https://digitalcommons.mtu.edu/wolf-annualreports

\section{Recommended Citation}

Jordan, Peter A., "Studies of the Moose and Wolves of Isle Royale, 1964-1965" (1965). Ecological Studies of Wolves on Isle Royale. 57.

10.37099/mtu.dc.wolf-annualreports/1964-1965 
STUDIES OF THE MOOSE AND WOLVES OF ISLE ROYALE*

Second Annual Report

1964-65

by

Peter A. Jordan, Research Associate Department of Forestry and Conservation Purdue University

Lafayette, Indiana

17 May 1965

* Receiving principal support during the current year from the National Geographic Society Committee for Research and Exploration, the National Park Service, the National Science Foundation (G-23558), and the Wildlife Management Institute. 
This report covers principally the second year of a threeyear investigation of the ecology and dynanics of the moose in Isle Royale National Park. In the annual report for 1963-64. there was a brief recounting of past work on the island by Purdue University personnel. Headed by $\mathrm{D}$. L. Allen, the long-term program has included $L$. D. Mech's research on wolves, completed in 1962, and P. S. Shelton's study of the beaver completed in 1963. In both past and present work inforination on moose, particularly population dynamics and the characteristics of wolskilled individuals, has been collected. Likewise, observations on the wolres have been made with a continuity of approach through the seven years of study. In this year's report in addition to current findings, some longer-terin summaries are given.

\section{Work Progress $1964-65$}

Field work for this report period commenced with three weeks of ground work in May, 1964. On plots laid out the previous fall, pellets of both moose and hares were counted and cleared. Ground search was made for moose in order to determine over-winter survival and sex ratio in the cali crop of the previous summer. One moose was autopsied in liay, and, during the many miles of cross-country hiking, a number of remains were discovered and examined. Fragmentary data on wolf activities were also obtained. During the summer, observations of moose were continued; more carcasses were examined; new pellet-count plots were laid out and described; and, during the fall, most plots were again counted and cleared. In september and October, Larry Roop, an undergraduate at Purdue was employed as field assistant. In late October, five days were spent making aerial herd composiiion counts using a Piper cub piloted by nilliam J. riartila of Eveleth, iinnesota. During summer and fall significant new observations were made on wolf reproduction. Working with us during the summer were two students on the National Science Foundation undergraduate research progran. Erilk Stauber, in his second summer on the island, continued his survey of birds of prey, while William seitz trapped and studied beavers in certain of Shelton's study colonies. The three of us were able to coordinate our various projects efficiently.

The work schedule in winter 1965 was essentially the same as in past years. We arrived on the island February 2 and departed March 23, with Dr. Allen being present the iirst four weeks. Winter work consisted principally of following and observing wolves, locating and examining kills, and censusing moose. It was carried out irom an Aeronca Champion ski-equipped plane operated by our skilled pilot and observer Donald E. Murray who was with the program for his seventh winter. Also participating in the winter operation were chief naturalist william W. Dunmire, radio technician Richard in. Igo, and ranger Jon B. Abrams. Although we were plagued by an unusual amount of stormy weather, our total flying time of 140 hours was not below average for 
past years. Observational contact with the wolves was interrupted several times for two- and three-day spans. Normal amounts of ice were present on bays and shores; however the surfaces were unusually rough for landing, and the aircraft sustained certain damage from this.

\section{Numbers, Dynamics, and Condition 으 Moose}

This study is concerned with population dynainics, pathology, habitat relationships and behavior of the noose. particular attention is being given to the numbers and health status of moose killed by the wolves.

Production and survival of calves in 1964-65

As was pointed out in the previous report, an estimated minimum ratio of 100 calves per 100 adult cows was found throughout the summer of 1963, indicating a natality somewhat higher than average arnong moose herds studied elsewhere. In 1964 an even higher birthrate was indicated. Between June 6 and Septernber 29, 75 cows and calves were classified, from which a ratio of 97 calves per 100 cóws was calculated. Yearling cows, according to records from the previous winter and spring, comprised approximately.23 percent of adult females. When these are excluded, becáuse they are reproductively immature, the ratio per 100 maturé cows was 129: calves. Since sample sizes were relatively small, the estimates are only approximate. All factors considered, however, this nataility estimate probably is conservative because counts ranging over a period of three months do not account for early losses, and young calves are proportionally more difficult to observe. Of the 25 cows found with calves, at least 12 (48 percent) had twins. -Some of the remaining singles could have been survivors of original twins. It can safely be stated that 1964 witnessed an unusually large calf crop. possibly 25 percent or more. above 1963.

Losses in this large crop were undoubtedly heavy between early summer and Inid-autumn. One indication of this was the number of current calf carcasses found during the period. There were six such animals in 196:4 as compared to a total of eleven in all the six previous summers combined. One of these six calves was killed by wolves. Reliable reports were received on two additional calf kilis, but carcasses were not located. Among the five nonwolf jills, one may have drowned, one had suffered a compound fracture of the right metatarsus, another was probably separated from its cow by human disturbance, and in the remaining three no mortality cause could be determined. In the instance of the wolf kill, valuable observations were made by seasonal ranger, $K$. $M$. Pietila, on a violent battle between the calf's mother and some three to Eive wolves. 
Aerial herd composition counts in late October showed an estimated 2.5 calves per 100 cows, or on the same basis as above, 32 calves per 100 nature cows. This indicates that many calves died during the first five months aiter birth. Though the Figures are somewhat rough, differences of this magnitude leave little doubt that a large proportion were lost.

A suitable explanation for such heavy losses following high natality, including an apparently high non-predatory toll, can not now be suggested. It does not appear that a decline in the welfare of the herd as a whole was involved. Census estinates plus the condition of animals examined in winter, contradict such a supposition. Records of the past seven years.show that fluctuations in production and survival have been common. If nothing else, it is of interest to know that a moose population subject to continuous, effective predation does demonstrate such variability.

In the late winter period, February-piarch, calves constituted 10 percent of the total population. Only in 1961, at which tine ijech found 10.5 percent, has the ratio been that low; in the other winters observed ratios were from 17 to 27 percent. In Iate October 1964, calves conprised an estimated 12 percent. Rate of loss in calves during the intervening period thus appears to have been close to that in adults. Percentage incidence of calves in the 1965 winter kill was approximately equivalent to their incidence in the winter population. This constitutes a high survival rate for first winter young. When relatively few calves are present, contacts between calves and wolves are less; hence there are fewer opportunities for killing. The condition of cows may have been such that they were able to defend their calves more effectively than usual. Also heavy losses during summer and early fall uncioubtedly reduced calf pairs disproportionaltely so that cows which had born twins were left with but one calf to defend. From 48 percent in midsummer the incidence of pairs dropped to 12. percent by late October, and no twins at all were seen in the midwinter field work.

\section{Adult mortality}

On Isle Royale, wolf predation accounts for a large majority of adult moose losses. However there is great individual variation in vulnerability. These differences largely involve old age and pathology, the two factors being commonly interrelated. From the start of this project, a positive relationship between age and vulnerability has been evident. Specific pathological findings and their implications will be discussed under separate heading.

Determining the age of death of wolf-killed adults is a reçuisite for studying vulnerability relationships-- hence .. understanding the dynamics of predation. To date this has been done by relating age to the degree of tooth wear. Though valuable. this technique is not accurate enough for the type of analyses we would like to make. A newer method, promising to provide 
such accuracy, will be undertaken within the coming year. This consists of microscopic examination of tooth roots for annular patterns similar to the annual rings in trees. Then teeth from the 195 adultmoose remains now on hand have been analyzed, the age relationships of the entire collection will be reviewed.

In this connection, a point at issue is the appearance of young adults arrong the kills by wolves in winter. Prior to 1964 no animals between one and five or six years of age had been accounted for. In 1964 two yearling males were killed, and in 1965 one twoyear-old rnale and one three- or four-year-old male were killed. These records imply a downward trend in age of vulnerability, but a more reliable analysis will have to await the results of further age determination work. If such a trend is in progress, it inight indicate that very old aninals are less numerous than they were a few years ago-- a prolonged adjustinent to the advent of predation on this population around 1949 .

From records on moose of accurately determined age, it is expected that a life table for the Isle Royale moose herd can be constructed, giving a comprehensive picture of age distribution and turnover rates. Through March 1965, the following specinens have been collected during the seven years of the program:

I. Carcasses examined and teeth recovered:

a) Accounted for during winter studies:

$$
\begin{aligned}
& \text { Adults. . . . . . } 97 \\
& \text { calves - * * * } 32
\end{aligned}
$$

b) Accounted for at other times:

$$
\begin{aligned}
& \text { Adults . . . . . . } 98 \\
& \text { calves } \cdot \text { total }^{\cdot} \cdot 51
\end{aligned}
$$

II. Accounted for without recovering teeth or other a,e criteria . . . 16

III. Autopsies (not including animals fatally wounded

by wolves). . . 7

Total

301

Numbers of moose

In February and March, 1964, a limited aerial survey of moose was carried out by counting ten sample plots ranging in size from 0.82 to 7.73 square miles. The flight pattern was principally by strips, but on occasion more intensive searches by circling were made. In 1960, Mech had covered the entire island by aerial survey. He counted 529 moose, and from this estimated the population at 600 . A comparison of 1964 results with the number of moose plotted on the same areas by Mech in 1960 gave a figure 17 percent higher for 1964. However, lack of statistical treatment prevented any firm conclusion on population trend. 
A more systematic sampling method was designed for 1965. Experience in counting during 1964 showed that, to obtain an acceptable level of accuracy, aerial searching had to be as intensive as possible. Not only was the strip method found inadequate, but even when all moose tracks seen along the strips were traced out, many animals could be missed. It was concluded that every piece of ground should be viewed several times from different directions. To accomplish this a flight pattern was employed wherein strips were covered with a circling course which allowed for ample overlap. Degree of overlap was increased with increasing density of cover and increasing numbers of fresh tracks. Since coverage of the entire island using this technique would have been impossible, the sampling was designed to cover a series of plots. The size of these was kept sma11, 0.25 to 0.50 square miles, for two reasons. Time to cover a plot should not exceed 20 minutes, because in continuous searching the observer's efficiency begins to drop with longer periods. And on larger plots this flight pattern gives rise to errors from the inability of the observer to keep track of sectors already covered. This is particularly true if the animals are moving. In most instances 700 feet was found to be a good flight altitude, though this was varied according to the situation.

The following environmental conditions were found to influence success in counting: First, when winds were greater than 15 wiles per hour, it was found inadvisable to make counts. with lesser winds, only plots along the windward shore were counted, because, as wind moves across the island's ridges, it creates turbulence above. The quality of snow surface was found to be critical. Animals were most easily spotted during the first day or two following a new snow of at least two inches. This was rela ted both to tracking and the ease of spotting animals against the texture of new snow. Less critical, but important, were quantity and quality of light for counting. A high intensity of light vas advantageous, but the glare from direct sunlight on snow impeded visibility. Optinal light was sufficiently direct to show shadows in the tracks but diffuse enough to minimize contrast between areas shaded and those exposed. A partial overcast seemed to produce the best light condition. Factors influencing the activity of moose-- hence their observability-- are not well understood. If possible, the timing of counts should coincide with periods of greatest activity. Even when all the above requisites are net, some moose are overlooked because of heavy cover or other conditions difficult to appraise. Nevertheless, it is believed that the counts made in 1965 gave more accurate results than have been obtained in most other aerial

census of moose.

The sampling plan $\cdot$ as initially designed consisted of 92 plots distributed somewhat uniformly over the island. Unusually inclement weather interfered with the flying schedule so that only 59 of these were counted. These, totaling 18.3 square miles or 8.6 percent of the island, yielded 76 moose. Extrapolated, this gave an estimated population of 848. Statistical analysis showed that, at the 95 percent confidence level, one could expect the actual population to be somewhere between 573 and 1123. This does not allow for animals missed through sampling inaccuracies. It probably is also subject to underestimation due to the fact that, among those 33 plots which could not be covered, average density was believed 
higher than that in the portion of the island which was sampled. Therefore, it appears that the 1965 Isle Royale winter moose population was conservatively somewhere between 850 and 1,000 . It will be recalled that this was a winter when calves were below "normal" in number.

Whether this estimate signifies an increase of moose since Mech's work in 1960, can not be ascertained. Much of the difference could be attributed to the more intensive inventory method. On the other hand, a statistical error is involved in extrapolating from a limited number of plots. Efforts are now in progress to refine this census method further so that limits of variance in the estimate will not be so wide. Using the data from 1965 counts, a statistical approach is being developed by $\mathrm{P}$. E. Dress, departmental statistician who will if necessary. employ a computer program to create the most efficient sampling design within specified limits of accuracy.

\section{Pathology}

A major objective in the moose studies has been to determine physiological and/or pathological conditions which may relate to predation vulnerability. This work has involved the examination of many dead moose remains in addition to several collected for autopsy. We are indebted for assistance in the pathology work to members of the Purdue School of Veterinary Science and Medicine, in particular to S. M. Gaafer who has processed and examined much of the material. Conditions being studied in detail include malnutrition as reflected by narrow fat depletion, occurrence of tapeworm cysts in the liver and lungs, lumpy jaw, and arthritis. Any of these may be instrumental in lowering the age at which moose become vulnerable to wolves.

Fat stores: Bone-marrow fat content probably is the best available index of general condition in the wolf-eaten moose. During winter 1965, marrow samples from several bones were preserved from each kill examined. These are to be analyzed for fat content to quantify the relationship between appearance and depletion. Of all adult moos e killed during winter 1965, only one had markedly depleted marrow. This one, interestingly, was the three- or fouryear old male, an animal of an age at which vulnerability has been lowest. It would appear that some pathological condition was involved in the vulnerability of this animal.

Two moose were collected for autopsy during winter 1965. One was a cow which, though not involved in a wolf attack, gave valuable information on the age category of animals not regularly taken by wolves. This animal was estimated as around four or five years of age, and she was carrying one fetus. Fat stores were greater and pelage condition better than in any moose yet examined in winter. The other animal collected was an adult bull well past prine age. This animal had been wounded, apparently fatally, by wolves. Its visceral and body fat reserves were low, particularly as compared with the other autopsied animal; although its bone marrow was not severely depleted. 
Tapeworiii cysts: Cysts of the bydatid tapeworn (Echinococcus granulosus) vere present in both of the autopsied moose; however, the level of parasitism was guite different for the two. The young cow showed but two cysts in the liver and one in the lungs. On the other hand, the old wounded bull had 74 cysts in the lungs and 24 on the surface of the liver. The lung cysts ranged up to 1.5 inches in diameter. A similarly heavy load, though not guite so great, was found by shelton in a moose which died after being injured by wolves. Any real appraisal of vulnerability due to cyst load will remain difficult or impossible, because the viscera are so seldorn available for examination in moose taken by wolves. collecting adecjuate numbers is both vulnerable and invulnerable classes of comparable ages in not feasible.

Lurnpy jaw: Deterioration of the jaw bone around molar teeth, a condition generally referred to as lumpy jaw (or necrotic stomatitis), has been found in some older animals of this herd. It was reported by viech and by Shelton during this study as well as by Murie for Isle Royale in 1929. There appears to be a close relationship between the impaction of woody food matter between teeth and adjacent bone and the initiation of necrosis. In some cases, however, a hole in the side of the jaw appears to be the starting point. Necrosis apparently then proceeds down into the nandible destroying bone around tooth roots until the marrow cavity is exposed. Remodeling of bone occurs, probably at the same time, and this eventually leads to an external swelling or the characteristic lumpiness. There may be extensive rarification of adjacent bone or abnormal wearing of teeth. In a few cases extensive decay of teeth was found.

It has appeared that this condition night result from infection with Actinomyces, though no report of isolation of this organism from moose has been found. It has presumably been found responsible for a similar condition in livestock. Fresh material showing several stages of the condition were obtained from winter kills in 1965 . and these were kept frozen. The specimens are now being studied by E. O. Haelterman of the School of Veterinary Science and Medicine at Purdue to determine the agent of this disease as well as to describe it.

A marked reduction in the incidence of lumpy jaw in 1963 and 1964 suggested that the condition was disappearing frorn Isle Royale. moose. However, four cases were found among kills in the winter of 1965. If a decline is in progress, more records will be required to demonstrate:it. The following table summarizes the occurrence of lumpy jaw in dead adult moose exanined during the winters 1959 through 1965. The incidence in carcasses examined at times other than winter is closely similar to this. 
Year Killed by Five or more !'olves liilled by less than five lolves
Total, inclurin? Denths of unknom $\mathrm{C}$-use

\begin{tabular}{|c|c|c|c|c|c|c|c|c|c|}
\hline & $\begin{array}{l}\text { Advanced } \\
\text { Necrosis }\end{array}$ & $\begin{array}{r}\text { Incipient } \\
\text { Neciosis }\end{array}$ & None & $\begin{array}{l}\text { Advanced } \\
\text { Necrosis }\end{array}$ & $\begin{array}{r}\text { Incinient } \\
\text { Nocrosis }\end{array}$ & None & $\begin{array}{l}\text { Advanced } \\
\text { Necrosis }\end{array}$ & $\begin{array}{l}\text { Tncipient } \\
\text { Necrosis }\end{array}$ & None \\
\hline 1959 & 0 & 0 & 7 & 1 & 0 & 0 & 1 & 0 & 7 \\
\hline 1960 & 1 & 0 & 5 & 1 & 0 & 1 & 2 & 1 & 6 \\
\hline 1961 & 1 & 3 & 5 & 1 & 2 & 3 & 2 & 5 & 8 \\
\hline 1962 & 1 & 4 & 5 & 0 & 1 & 1 & 1 & 6 & 9 \\
\hline 1963 & 0 & 3 & 9 & 0 & 0 & 1 & 0 & 3 & 11 \\
\hline 1964 & 0 & 0 & 10 & 0 & 0 & 1 & 0 & 0 & 13 \\
\hline 1965 & 1 & 4 & 6 & 0 & 0 & 1 & 1 & 4 & 7 \\
\hline Total & 4 & 24 & 47 & 3 & 3 & 8 & 7 & 19 & 61 \\
\hline
\end{tabular}

There seems to be some tendency for severe cases to be proport. tionally more frequent in moose killed by smaller groups of wolves. This could imply a direct influence on vulnerability-- the more advanced pathology enabling fewer wolves to make a kill. However, on the average, more severe cases occur in older animals, and these may be more vulnerable for other reasons. Better determinations on these questions can be made when more accurate age determination becomes possible, especially in the older age classes of moose.

Arthritis: This condition, occurring with significant frequency, is another type of pathology which in all likelihood greatily influences vulnerability. The finding of arthritis was described briefly in the 1964 report, and since then new cases have appeared. One of these was a cow killed by a pack of five on the ice of a small bay in February. In this animal there was no left acetabulum, the deep socket on which the thigh bone articulates with the pelvis. Degeneration and reshaping had left a completely flat surface in its place. Either an alternate articular structure had developed in soft tissues, or the hind limb of this animal was completely useless. Condition of the cow's bone marrow indicated that advanced malnutrition was not involved, so it is assumed the animal had been moving about satisfactorily to meet its forage needs. In any event, the ability of a moose so afflicted to run from or to defend itself against five wolves is much in question.

Since discovery of arthritis in this herd, efforts have been made to deternine its incidence. In 29 adults cound dead from natural causes and in which determinations could be made, 9 have shown some degree of this condition; the majority of these were advanced cases. In conjunction with G. M. Neher of the Purdue veterinary School, this condition will be described, and Dr. Neher will attempt to determine what pathogen, if any, is involved. 
Miscellaneous parasites: Besides the specific objective of defining parameters of vulnerability, general studies of parasites and diseases are underway. For example efforts were made this past winter to determine the presence of a lungworm, pneumostrongylus tenuis, which has recently been reported as causing "moose disease". An examination for eggs of this worn: in moose feces collected from Isle Royale was carried out by P. D. Karns and his colleagues of the Minnesota Department of Conservation; Further samples will be sent to them in the corning summer and fall. These men originally pointed out the relationship between inoose disease and pneumostrongylus in linnesota. First results indicate that the lungworm is not present in Isle Royale specimens. The symptoms of moose disease have never been reported from the island.

Studies of this past winter indicated an unusually low incidence of winter ticks. On two animals autopsied few ticks could be found, in contrast to other winters when specimens examined were carrying hundreds or even thousands of ticks. Ordinarily in February and March the majority of moose show a rough pelage with extensive bare spots; these latter are presumed to have been rubbed in response to tick irritation. Of the many moose seen frorn the air and on the ground this past winter, a great majority showed smooth and undisturbed pelage.

During the summer of 1964, leeches were observed attached to the hind legs of moose feeding in ponds. Close observation was possible in several instances. It is suggested that leeches cause the heretofore unexplained open sores which are prevalent on hind legs of moose during summer. Such sores may be kept ofen by repeated inrnersion and by the feeding of an insect believed to be the moose $f$ ly. Haematobia alcis. This fly occurs in large swarms about each adult moose and has been observed concentrated on the sores. In September. an observation was made of a female redwinged blackbird walking about the back of a moose eating moose flies. This series of observations thus constituted a record of an interesting chain of animal interactions.

Social behavior of Moose

During the rutting season in fall 1963, a number of opportunities arose for close observation of breeding behavior. In 1964 such observations were not possible, mainly due to nearly continuous stormy weather. Between october 23 and 27, 1964, during a few days of fair weather, aerial herd composition counts were made. of all cows classified at this time, 42 percent were in the company of bulls, and of all mature bulls, 56 percent were in the company of cows. In contrast, during the fall counts of 1963 which were flowh on the same dates and in similar areas, the incidence of cow-bull associations was 23 percent for cows and 28 percent for bulls. This may reflect an extension of the rutting season in 1964, although rutting activity did not begin later than in 1963. Such extension may have occurred because the unusual amount of stormy weather interfered with or interrupted normal sequences of breeding behavior. It will be interesting to note whether a corresponding difference in time of calf drop can be detected in spring of 1965. 
Pellet-vegetation plots

A small sampling program has been initiated to study distribution and relative numbers of moose and hares and, at the same $t i m e$, to study vegetation as it relates to these animals. To date 349 plots have been laid out on 25 lines located in widely separated parts of the island. These lines consist of from 10 to 20 plots spaced 200 feet apart. Each plot is marked with a 3-Foot, heavy metal stake to insure some degree of permanence. Both stakes and spots. on adjacent trees are painted orange to facilitate rapid relocation.

Droppings of moose are counted and then cleared from the plots once a year (fall) or, when convenient, twice a year (fall and spring). This is a standard nethod in big game work for measuring frequency of occurrence; it has been used previously for studying moose on Isle Royale by $L$. W. Krefting of the U. $\mathrm{U}$. Bureau of Sport Fisheries and Wildlife. It can in some circumstances be used to estimate animal numbers.

The pellet plot consists of a 15-foot radius circle 10.162 acres) around the stake. A pellet group, that is, all the pellets dropped in one defecation, is considered one unit. Then scattered groups are only partially within the plot, the estimated fraction is recorded. Feces of moose in suinmer are usually amorphous as contrasted to the pellet-form dropped at other seasons; thus it is possible to distinguish the season of an area's usage. In order to estimate population numbers from these counts, defecation rates Inust be determined. Efforts to accomplish this by winter tracking during known periods are now in progress, but adequate information has not yet been obtained.

Hare pellets are counted individually and then cleared from within a 2.5-foot-radius circle around each stake. No attempt will be made at present to extrapolate these counts into population estimates. If the plots are checked annually over a number of years, then presumably fluctations in the numbers of hares can be determined, and such in turn could be compared for synchrony with mainland populations.

A description of vegetation is being made within a 15-foot radius at each plot. All measurements are by visual estimate; hence figures are not precise. Data are recorded for all woody species and for the most common herbaceous species, the remainder being lumped into broader categories. Plants are recorded according to height classes being designated as greater than $1,2,6,10$, 15. and 35 feet above the ground. Species abundance is indicated according to estimated ground-area intercept. The main purpose of these descriptions is to provide an index of types and quantities of forage available.

Intensity of usage, if any is recorded subjectively as somewhere between very light and very heavy. Where the season in which foraging took place is evident, this is recorded, and distinction is made between inoose and hare usage. plants with a third or more of the crown branches dead are listed as decadent, and recently-dead plants are so recorded. Trees blown down recently are recorded with notation as to whether they were alive or dead at the time of falling. 
These plot lines for pellet counts and vegetation analysis are being established with a long-term outlook. Initial readings contribute relatively little to present studies, but it appears likely that the work can be kept up as part of the routine park research program or otherwise.

In this light, the system can provide information on major population trends and shift of moose and hares. It can likewise Furnish an index of vegetation use by these browsers and an insight into successional trends which will strongly influence food availability in the future. Such information will be needed in the managernent decisions of years to come.

Predatory Habits, Population Dynamics, and Social Behavior of Wolves

In the present three-year phase of the Isle Royale research program, primary concern is with the noose herd. However, as a logical part of this objective, information on the wolves continues to be accumulated. The wolves have a vital role as predators, and their status is pertinent in the ecology of the moose. Every effort is being made to obtain information on numbers and reproductive success as well as on the hunting habits of the wolves. Beyond this, however, our study circumstances afford original observations on social behavior.

Wolf numbers and structure of the packs

Though it is possible to estimate rather closely the number of wolves on Isle Royale, it can never be determined if and when all are accounted for. There appeared to be an increase from winter 1964 to winter 1965. A minimum count of 25, the largest recorded during the years of this study, was made on February 27, 1965. It is believed that the actual population exceeded this by at least three. Data froin winter 1964. led to a ininimum estimate of 25 (26, including one known to have died in February). Circuinstances for counting during 1965 were less favorable, because flying weather and tracking conditions were poorer, and the structure of wolf groups was less stable.

In 1964 the large pack nurnbered consistently 20, after an initial count of 22 on February 2. In 1965, a maximum of 18 was seen on several occasions; one individual was often trailing or widely separated. Evidence acquired in early February indicated that actually two loosely-associated individuals might be present, giving a possible total of 19 for the large pack. Though the pack was 18 as seen most of the time, the picture was actualiy more complicated. On February 24, two wolves considered to be independent were feeding on a kill about a mile from the big group. These two, in response to howling, came toward and either joined with or passed through the ranks of the large pack. The next opportunity for a good count was on February 27 when 20 wolves were seen in the same vicinity in groups of $3,13,1$, and 3 . From the circumstance, it appeared that a reorganization of the previous groupings, 18 and 2, had occurred. If so, then the large pack 
inight have as rnany as 2.0 or even 21 individual wolves associated with it at one time or another. Another possibility is that the groupings seen on the 27 th included some animals snot previously accounted for.

Locating and distinguishing minor groups was especially difficult in 1965 because of weather interruptions and unfavorable tracking conditions. On a basis of sign, at the time 20 wolves were accounted for as above, it was estimated that as many as three additional aninals inight be present in the same vicinity.

Of most significant interest was the discovery of a new pack of five confined to the northeast sector during our observations and apparently separate from other groups. This brings the ininimum total to 25 for the island, but leads to a more realistic estimate of 28.

Most sightings of single wolves were either close to the large pack or in areas recently traversed by thein. Only one observation of a single was made elsewhere. Besides the two observed repeatedly near the large pack, four more sightings of pairs were nade. These were all in the central region of the island, but probably not the same animals in all sases.

Wolf population dynamics

In the early years of this study there was little or no evidence of reproduction and turnover in these wolves, and a relatively stable condition was assumed to exist. More recently, there has been convincing evidence of recruitinent and loss. Increases were observed in the total wolf population in both 1964 and 1965. Partial remains of an adult were found in March 1964. There was no evidence how this animal died but the teeth indicated it was advanced in years.

In July 1964, tracks of pups were discovered at Feldtmann Lake by Erik stauber, and shortly thereafter we discovered at the same site a dead wolf pup approximately three nonths of age. Examination revealed the animal to have been extremely emaciated, and death could have been due to starvation. During the same period, some 9 miles away, D. R. Kangas of the Park Service and others, while listening to wolves howl, believed that yips of pups could be distinguished. Although such distinction is difficult, MF. Kangas has had the experience of hearing wolves on a number of occasions.

On October 24, 1964, while making moose herd composition counts from the air, pilot Bill Martila and $I$ saw a pack of 15 wolves near Lake Halloran. Both He and I agreed that there were three pups in this group. Then, during winter 1965, repeated observations were made of four pups in the large pack, and the pack of five contained one. My ability to recognize pups had been aided by suggestions from two University of Chicago aniral behaviorists, Benson Ginsburg and Jerome noolpy, who are studying captive wolves. Unfortinat.ily, our discussions with them were held after the winter 1964 observations had been riacle. 
In years prior to 1964 only one pup had been described; this a member of the large pack in winter 1962. In 1964 we believed that certain of the large pack were pups. This was sonewhat anticipated since the pack had increased by as many as five from the previous winter. However, we did not have confidence in our ability to make this distinction and did not reach a positive conclusion concerning the presence of pups.

Breeding, which occurs in mid-February, has been noted in all years during which the large pack could be kept under regular. close surveillance. In 1964 the dominant or "alpha" male and one other were, at one time or another, observed in persistent breeding efforts. There was some interference by the alpha male with the breeding efforts of the others. The same approximate pattern was repeated in 1965. In the new pack of five, copulation resulting in coupling was oloserved on one occasion.

The 1964-65 observations indicate that at least three litters inay have been born in spring 1964. This involves two assumptions: first, that the one pup with the pack of five was the survivor of a litter probably born at the northeast end of the island, and secondly, that David Kangas did hear a pup or pups at a locale 9 miles from where a litter was known to be. Also indicating the presence of three litters is the evidence that among the four pups in the large pack, there was a tendency to split three and one. One appeared smaller, but it was not determined whether it was the single when the pups were split. Thus, the four may have come from two litters, in addition to that of the five-pack.

It is reasonable to suppose that the early progeny of wolves which immigrated to Isle Royale in 1949 survived in such numbers that they soon populated the island to capacity. In subsequent years, reproductive success may well have been nil. However, after fourteen or so years this generation would be dying out, and replacements could be coming on rapidly. In the absence of more precise information, the pattern of population turnover rnust remain speculative.

The finding of a supposedly starved pup, plus the regular observation of breeding activity, does suggest that failure of pups to survive rather than failure of adults to breed is the principal factor in population stability. This is suggested even though we observe the alpha male interfering with the breeding of others; actually, he himself could be responsible for a number of pups each year. The increase in wolf rumbers may possibly be related to an increase in available food. The higher figures of the recent moose census may indicate a real increase which could have provided spring and summer food adequate to allow a degree of success in raising of pups not previously possible. Even were the moose population not greater, if its reproductive rate had increased, then there should be more food available to the wolves. It is suggestive to associate the large calf crop of 1964. showing heavy losses duringthe early months, with the survival of five wolf pups into the following winter. 
Rate and aistribution of kills

In a 44-day observation period the large pack, or parts thereof, killed at least 11 and probably 12 moose. One of these was a calf, and two rnore may have been. An adult bull was shot for autopsy after it had been wounded so severely that there can be little question of its soon falling to the wolves. One moose seen dead but not examined had not been fed upon; however the large pack had been active in the vicinity and may have injured it. Between February 7 and 11 the wolves were not seen feeding; yet on the latter date they were observed defecating heavily. This strongly indicates that a moose had been devoured within the previous couple of days. They probably killed and finished up a moose, possibly a calf, while we were grounded. In the calculations which follow, it was assumed that a calf was eaten.

To determine whether rates of consumption by wolves variec between 1964 and 1965, calculations were made to estimate the average poundage of moose eaten per wolf per day. Weights of moose are based in part on figures used by Mech. Because unconsumed parts are believed greater than his estimates, net edible weights (pounds) which follow are 10 to 15 percent lower than those used by Mech: calves, 250; yearlings, 550; nature cows and young bulls, 700; and mature bulls, 850 . Consumption rates were found to average nearly the same between the two years: 10.5 pounds in 1964 and 10.6 in 1965.

In 1964 the pack of 20 made $\bar{a} \mathrm{kill}$ on the average of once every 2.9 days, while in 1965, with 17 or 18 animals, the rate was every 3.5 days. Such a comparison can not be made with precision because of occasional splitting up in 1965. There was less variance in the frequency of kills in 1964 when the longest period between kills was six days. In 1965 the longest interval was 9 or ten days. Distances traveled between kills in 1964 averaged 19.6 miles with a maximum of 45, while in 1965, as best it could be figured, the average was 22.4 with a maximum of 79 miles.

As has been the case in past years, less is known of the predation rate for the smaller groups of wolves. The pack of five was discovered at the carcass of an adult half eaten on February 22, and they left this kill 9 days later. Eleven days after that, the remains of another kill, age as yet unknown, were discovered nearby. Presumably the five had made and finished this kill during the interval. If, in the future, this group remains intact and separate from the large pack, and if flying conditions are more favorable than in 1965, information comparable to that secured on the large pack may be forthconing. 
Ranges of the packs

The area occupied by the large pack or parts thereof in 1965 closely coincided with that of the year before. Ice conditions in 1965. being more typical of past years than in 1964, permitted access to outer islands and shortened routes across bays. The distribution of kills varied between 1964 and 1965 as it has ariong all previous year. In the former year the bulk of mid-winter kills occurred along the southern shore of the southwest end of the island, including the southwest end of Siskiwit Bay. In 1965 the greatest number occurred in the Malone Bay-Siskiwit Lake region.

It would be interesting to know whether certain areas in which many kills are made one winter are found by the wolves to be less productive in the years immediately following. In 1965 there was no lack of moose in the region of heavy killing the previous year. on the other hand, there could easily have been a qualitative change in the animals using these sites, thus accounting for any difference in hunting success.

The "new" pack of five appears to be exploiting a region which has not been hunted in mid-winter by the large pack since 1960. However, small groups have been seen there regularly. In early March the tracks of five or more wolves were seen on lake Richie. This is an area lying half way between the known range of the pack of five and the northeastern boundary of the large pack's range. The wolves in question could have been the fivepack or a subgroup of the large pack.

Other small groups and single wolves tended, as in 1964, to range within the central sector of the island. The proximity of some of these to the large pack was discussed above.

Social behavior in wolves

A noteworthy change in behavior occurred within the big pack between 1964 and 1965, and this may lead to significant changes in its stability and leadership. In 1964, members of the big pack all participated extensively in greeting gestures, play, and harassment of subordinate individuais. In contrast there was very little of such socializing observed in 1965, even though four pups were known to be present. Also in 1964, during February and March, the pack of 20 remained consistently intact. In the same period of 1965, the 18 were separated into subgroups several times. Once a group of 11 traveled 35 miles and were apart from the others for seven days. During that period, oone session of widespread play. greeting, and harrassment was observed among the 11 .

Corresponding to these differences were differences in the behavior of the dominant or alpha male. This large wolf, recognizable individually from the air, assumed his role in the complete sense during 1964. However, in 1965, he lagged behind, did not inix with the others as nuch, and in general did not assert himself nearly so much as before. Yet he would still have to be classified as the most dominant of the group. During the several instances of splitting up, he was with, or accompanied by, only one or two others; the instance of socializing among the subgroup of 11 may have been associated with his absence. 
One interpretation of these observations is that the alpha male is aging and -losing the enthusiasm or energy necessary to assert himiselif as before. The pack, in turn, is reacting to this change with uncertainty and insecurity: its social well-being has been disturbed. If such is true, it has noi affected the pack's ability or willingness to hunt or to kill moose. We may be witnessing a transition to new leadership or to new structure. The appearance of the five-pack may have been one result already. This is probably a farnily group which separated recently from the large pack. If extent of general play is an index of social wellbeing, then the five-pack by all appearances is a well adjusted group.

\section{Studies in Prospect ior 1965-66}

During the colring year llost of the work described here will be continued. As stated, plois will be counted as before and, if feasible, a few nore may be added. Special efforts will be made'. to get estimates of natality and survival and to further inprove the census program. During the coming suinner, the primary objective of our undergraduate assistants will be to investigate areas in which wolves may be denning, thus pursuing the discoveries made last summer. Toward the end of the corning report period, nuch time will be devoted to rinal reports and publications. 